\title{
Miscibilidade de Glicerina em Petróleo
}

\author{
Paulo César Correia de Matos
}

Instituto de Química, Universidade Federal da Bahia, Campus de Ondina, Salvador - BA - Brasil, CEP 40170-290 (matosengquim@yahoo.com.br)

\section{Objetivo}

Avaliar o desenvolvimento dos trabalhos de pesquisa e proteção a propriedade intelectual em relação a miscibilidade do petróleo com a glicerina ao longo dos tempos.

\section{Escopo}

Foram analisadas 150 patentes em maio de 2007, com as palavras-chave petrol* ${ }^{*}$, glycer* $\mathrm{e}$ o código $\mathrm{C} 10$ no banco de dados Espacenet.

\section{Aspectos tecnológicos}

Miscibilidade é a habilidade de duas ou mais substâncias se misturarem entre si e formarem uma ou mais fases.

No petróleo há predominância de carbono e de hidrogênio ( $\mathrm{CxHy}$ ).

A glicerina ou glicerol é um álcool (C3H8O3).

Tabela de pesquisa por palavras-chave e código de classificação internacional

\begin{tabular}{|c|c|}
\hline Palavras-chave e código & Espacenet \\
\hline petrol* & 48666 \\
\hline miscibil* & 1501 \\
\hline coal* oil* $^{*}$ & 11519 \\
\hline addit* & $>100000$ \\
\hline solve ${ }^{*}$ & 342 \\
\hline glycer* & 16878 \\
\hline water* product $^{*}$ & $>100000$ \\
\hline ternary* diagram* & 580 \\
\hline temp* & $>100000$ \\
\hline petrol* miscibil* & 42 \\
\hline petrol* addit* & 7239 \\
\hline petrol* $^{*}$ addit* solve* & 1939 \\
\hline addit $^{*}$ solve* and C10 & 547 \\
\hline petrol* addit* solve* glycer* & 193 \\
\hline petrol* glycer* water* product* & 76 \\
\hline petrol* glycer* and C10 & 150 \\
\hline
\end{tabular}


1. Patentes por Inventores

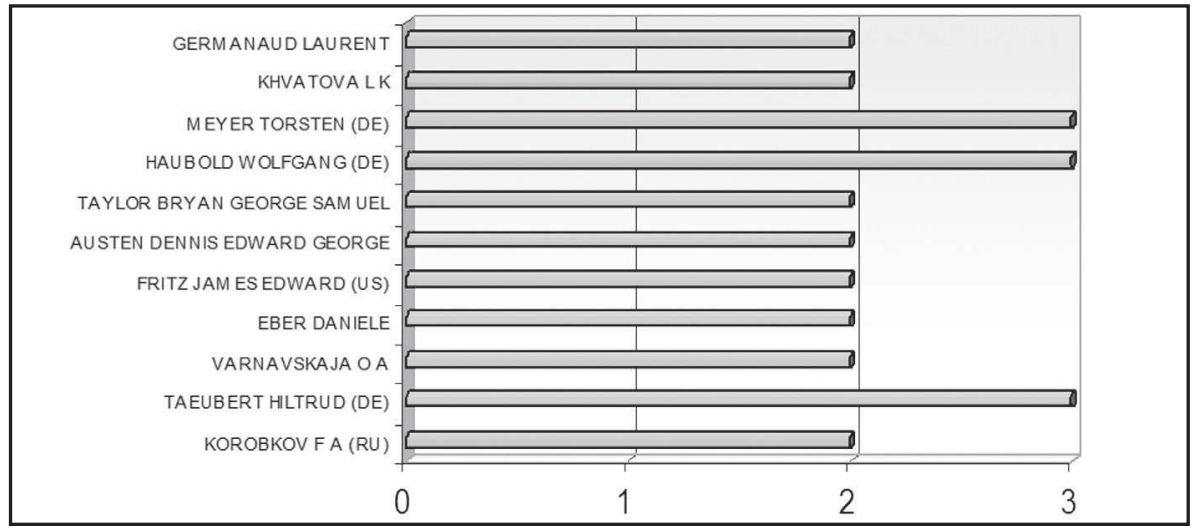

\section{Patentes por Empresa Depositante}

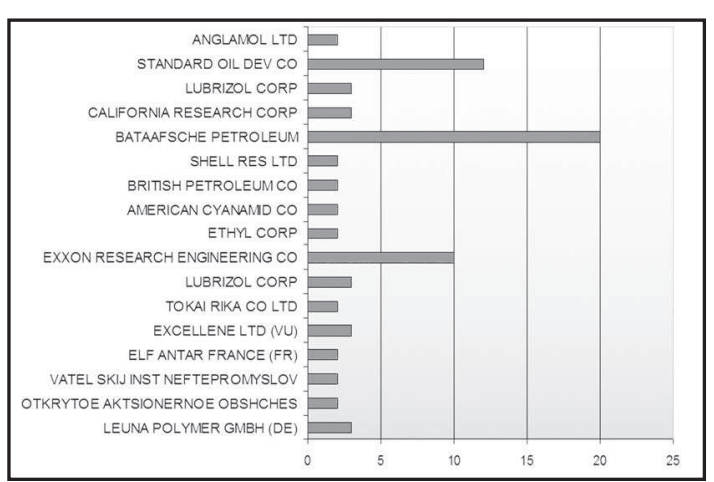

3. Evolução de Depósitos de Patentes por País

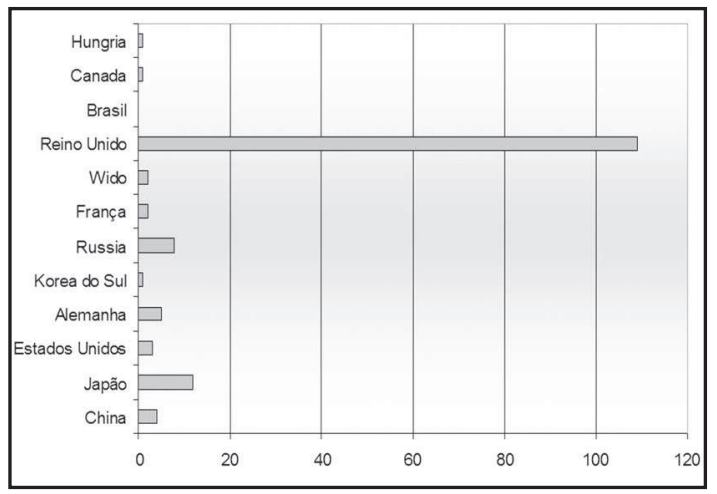

\section{Evolução Anual de Depósitos de Patentes}

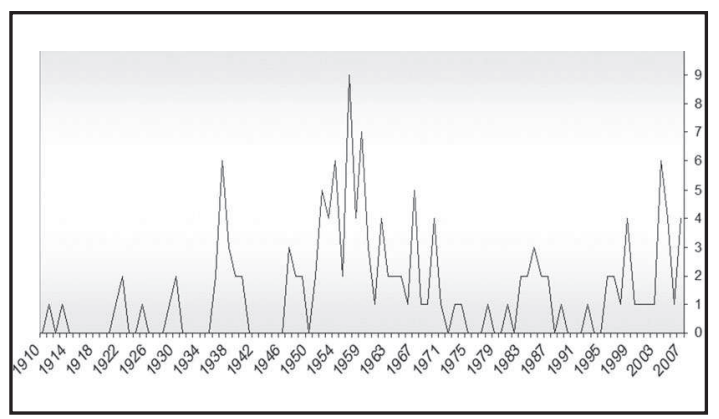

5. Patentes por Códigos mais Relevantes

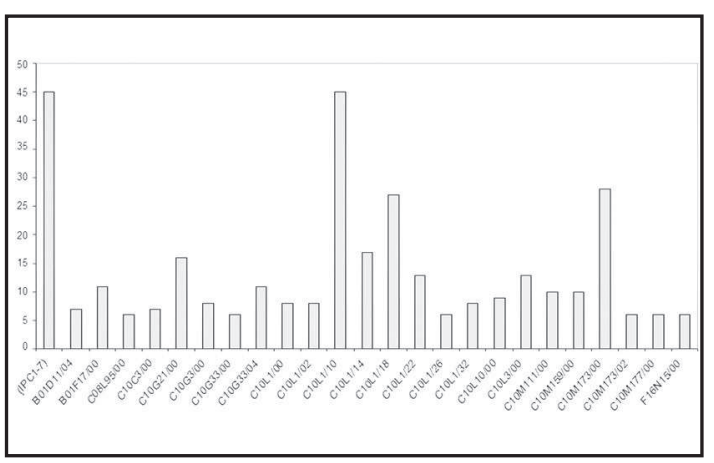

6. Patentes por Assunto

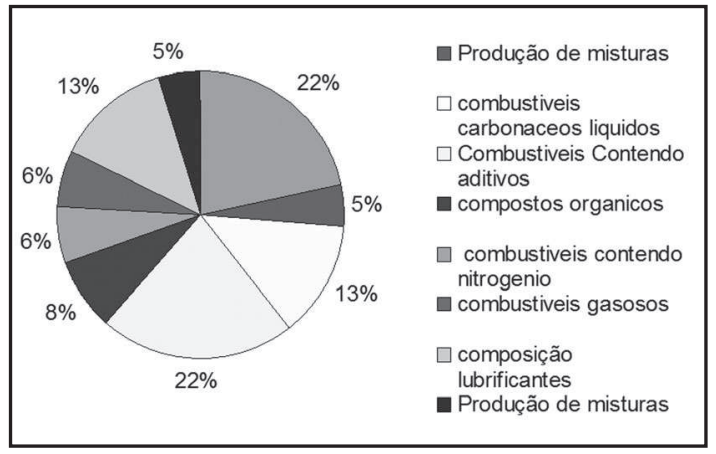

cunclusões

0 depósito de patentes apresentou maior input na década de 50, tendo o Reino Unido o pais que mais depositou patentes.

Entre os maiores inventores se destacaram os Alemães.

Paulo Correia de Matos é aluno de graduação em Engenharia Química da UFBA e aluno de Iniciação Científica no LabLaser do Instituto de Química da UFBA. Este trabalho foi realizado no semestre de 2007.2 durante a disciplina optativa "Marcas, Patentes e Propriedade Industrial" ministrada pela Profa. Cristina M. Quintella. Não tinha tido contato anterior com o tema. 